\title{
Diagnóstico pré-natal da osteogênese imperfeita tipo 2: relato de caso
}

\author{
Prenatal diagnosis of osteogenesis imperfecta type 2: case report
}

\author{
Caroline Mombaque dos Santos ${ }^{1,2}$, Francisco Maximiliano Pancich Gallarreta ${ }^{1,3}$, Wendel Mombaque dos Santos ${ }^{1,4} \bowtie$, \\ Caroline Eckerdt Schroer ${ }^{1,5}$, Edson Nunes de Morais ${ }^{1,6}$ \\ ${ }^{1}$ Universidade Federal de Santa Maria (UFSM), Santa Maria, RS. \\ ${ }^{2}$ Médica Ginecologista e Obstetra, Especialista em Medicina Fetal, Mestranda do curso de Mestrado Profissionalizante em Ciências da Saúde da UFSM. \\ ${ }^{3}$ Médico Ginecologista e Obstetra, Doutor em Obstetrícia, Professor Adjunto da UFSM. \\ ${ }^{4}$ Doutorando do curso de Doutorado em Enfermagem em Saúde do Adulto da Universidade de São Paulo (USP), Enfermeiro do Trabalho do Hospital Universitário de \\ Santa Maria, UFSM. \\ ${ }^{5}$ Médica Ginecologista e Obstetra, Especialista em Medicina Fetal, Mestranda do curso de Mestrado Profissionalizante em Ciências da Saúde da UFSM. \\ ${ }^{6}$ Médico Ginecologista e Obstetra, Doutor em Obstetrícia, Professor Titular da UFSM.
}

\section{RESUMO}

Objetivos: Descrever um caso de diagnóstico pré-natal da forma letal de osteogênese imperfeita.

Descrição do caso: Uma gestante de 26 anos, de cor negra, casada, do lar, previamente hígida, em sua terceira gestação, foi encaminhada com idade gestacional de 29 semanas e cinco dias ao Serviço de Medicina Fetal do Hospital Universitário de Santa Maria devido à hipótese de crescimento intrauterino restrito. A ultrassonografia obstétrica complementada pela ressonância magnética permitiu o diagnóstico de osteogênese imperfeita tipo 2, com crescimento intrauterino restrito, peso fetal abaixo do percentil 3 e deformidades ósseas importantes. A gestante foi submetida à cesariana com 33 semanas de idade gestacional. O recém-nascido, com peso de $1.120 \mathrm{~g}$, foi a óbito por insuficiência respiratória logo após o nascimento.

Conclusões: A osteogênese imperfeita é uma doença do tecido conjuntivo que cursa com formas letais e não letais, e o diagnóstico por imagem no pré-natal possibilita o aconselhamento familiar quanto ao prognóstico e a programação para o parto. O relato deste caso é importante para a comunidade científica, visando ao apoio no manejo de casos semelhantes.

DESCRITORES: osteogênese imperfeita; anormalidades musculoesqueléticas; ultrassonografia pré-natal; imagem por ressonância magnética.

\section{ABSTRACT}

Aims: To describe a case of prenatal diagnosis of the lethal form of osteogenesis imperfecta.

Case description: A 26 year-old pregnant woman, black, married, housewife, previously healthy, in her third pregnancy, was referred with 29 weeks and five days of gestation to the Fetal Medicine Service of the University Hospital of Santa Maria, due to hypothesis of intrauterine growth restriction. Obstetric ultrasound, complemented by magnetic resonance, allowed the diagnosis of osteogenesis imperfecta type 2, with intrauterine growth restriction, fetal weight below the $3^{\text {rd }}$ percentile and major bone deformities. The patient underwent a cesarean section at 33 weeks and four days of gestation. The newborn infant, weighting $1120 \mathrm{~g}$, died due to respiratory failure immediately after birth.

Conclusions: Osteogenesis imperfecta is a connective tissue disease that courses with lethal and nonlethal forms, and prenatal diagnostic imaging enables family counseling regarding prognosis and programming the type of delivery. Reporting this case is important to the scientific community, in order to support the management of similar cases.

KEY WORDS: osteogenesis imperfecta; musculoskeletal abnormalities; ultrasonography, prenatal; magnetic resonance imaging. 


\section{INTRODUÇÃO}

A osteogênese imperfeita (OI), ou "doença dos ossos de vidro" é uma patologia do tecido conjuntivo, com incidência de 1:20.000 a 1:50.000 nascidos vivos, que afeta igualmente ambos os sexos e apresenta como principal fator etiológico mutações no gene do colágeno tipo I, as quais causam defeito na sua biossíntese [1,2].

Atualmente há evidências de novas formas de apresentação da OI, porém a classificação frequentemente utilizada é a de Sillence et al. [3], subdividindo-se em quatro tipos, embora haja descrição de até 11 variações $[1,3,4]$ :

- Tipo I: forma mais branda e frequente da doença $(80 \%)$, com osteopenia leve e aparecimento de fraturas com o iniciar da deambulação, não modificando a estatura final do indivíduo, além de apresentar escleras azuladas, surdez em cerca de $30 \%$ a $50 \%$, podendo ou não estar associada à dentinogênese imperfeita.

- Tipo II: forma letal perinatal devido principalmente à insuficiência respiratória, com identificação ainda intrauterina de fraturas e deformidades ósseas.

- Tipo III: forma altamente limitante, mas compatível com a vida, na qual ocorre deformidade dos ossos longos e dentinogênese imperfeita.

- Tipo IV: semelhante ao tipo I, compatível com a vida, porém com escleras normais.

O diagnóstico pré-natal da OI pode ser aventado pela simples suspeita de crescimento intrauterino restrito (CIUR) em consulta de rotina pré-natal. Chamar atenção para esse fato é importante, já que a maioria das gestantes de fetos malformados não apresenta fator de risco [5]. A ultrassonografia apresenta sensibilidade de $94-96 \%$ na detecção pré-natal da OI, podendo ser usada também a ressonância magnética para apoiar o diagnóstico $[1,6]$.

A publicação deste caso foi aprovada pelo Comitê de Ética em Pesquisa da Universidade Federal de Santa Maria sob o parecer consubstanciado de número 869.318, com base na Resolução 466/2012 do Conselho Nacional de Saúde e mediante assinatura pela gestante do termo de consentimento livre e esclarecido.

\section{RELATO DO CASO}

Paciente de 26 anos, de cor negra, casada, do lar, previamente hígida, na terceira gestação, tendo tido previamente dois partos vaginais sem intercorrências, foi encaminhada ao atendimento pré-natal de alto risco do Hospital Universitário de Santa Maria (HUSM) por suspeita de CIUR. A altura uterina era de $20 \mathrm{~cm}$ com 29 semanas e cinco dias de idade gestacional, de acordo com a única ultrassonografia prévia de 12 semanas. Negava doenças e usava apenas sulfato ferroso profilático.

Realizado exame ultrassonográfico obstétrico que evidenciou CIUR, com peso fetal estimado de 742 gramas, abaixo do percentil 3 para a idade gestacional. Perfil hemodinâmico fetal de 0,87, Doppler das artérias uterinas com incisura protodiastólica apenas à direita $\mathrm{e}$ ossos longos curtos com alterações em sua conformação (Figura 1), deformação da calota craniana à mínima pressão do transdutor em abdome materno (Figura 2), mostrando pouca mineralização óssea, com pequenas fraturas e tórax em sino (Figura 3).

A partir desses achados, teve-se como hipótese diagnóstica OI tipo 2, sendo sugerida à paciente a possibilidade de estudo genético; entretanto, a mesma não consentiu na realização de amniocentese para realização antenatal do cariótipo fetal.

A ressonância magnética fetal, embora pouco útil para avaliação de displasias ósseas, foi realizada com o intuito de excluir outras anomalias, ocultas à ultrassonografia. A ressonância magnética evidenciou uma calota craniana adelgaçada e desproporção na relação tórax e abdome, com relação cardiotorácica de 1:1. Não se observaram as estruturas ósseas dos membros (Figura 4).

A gestante seguiu acompanhamento no setor de Medicina Fetal do HUSM, o qual é composto por equipe multidisciplinar, responsável pela preparação para o nascimento de um bebê malformado, com apoio à mãe e à família, inclusive para o luto.

Às 33 semanas e quatro dias de idade gestacional, a paciente foi hospitalizada no Centro Obstétrico do HUSM, por trabalho de parto pré-termo. Realizado novo exame ultrassonográfico, no qual o feto apresentava as mesmas características anteriores e CIUR (Figuras 5 e 6).

A paciente foi então encaminhada via Central de Leitos do Estado para outro hospital, pelo diagnóstico de trabalho de parto pré-termo que não cedeu ao tratamento medicamentoso e pela impossibilidade de leito de unidade de tratamento intensivo neonatal disponível no HUSM. No serviço referenciado foi submetida à cesariana. O recém-nascido, de sexo masculino, pesou 1.120 gramas e foi a óbito logo após o nascimento, por insuficiência respiratória. Não foram realizados exames post mortem, como radiografias, que seriam importantes para reforçar a hipótese diagnóstica. A puérpera não consentiu necropsia por questões ideológicas. 

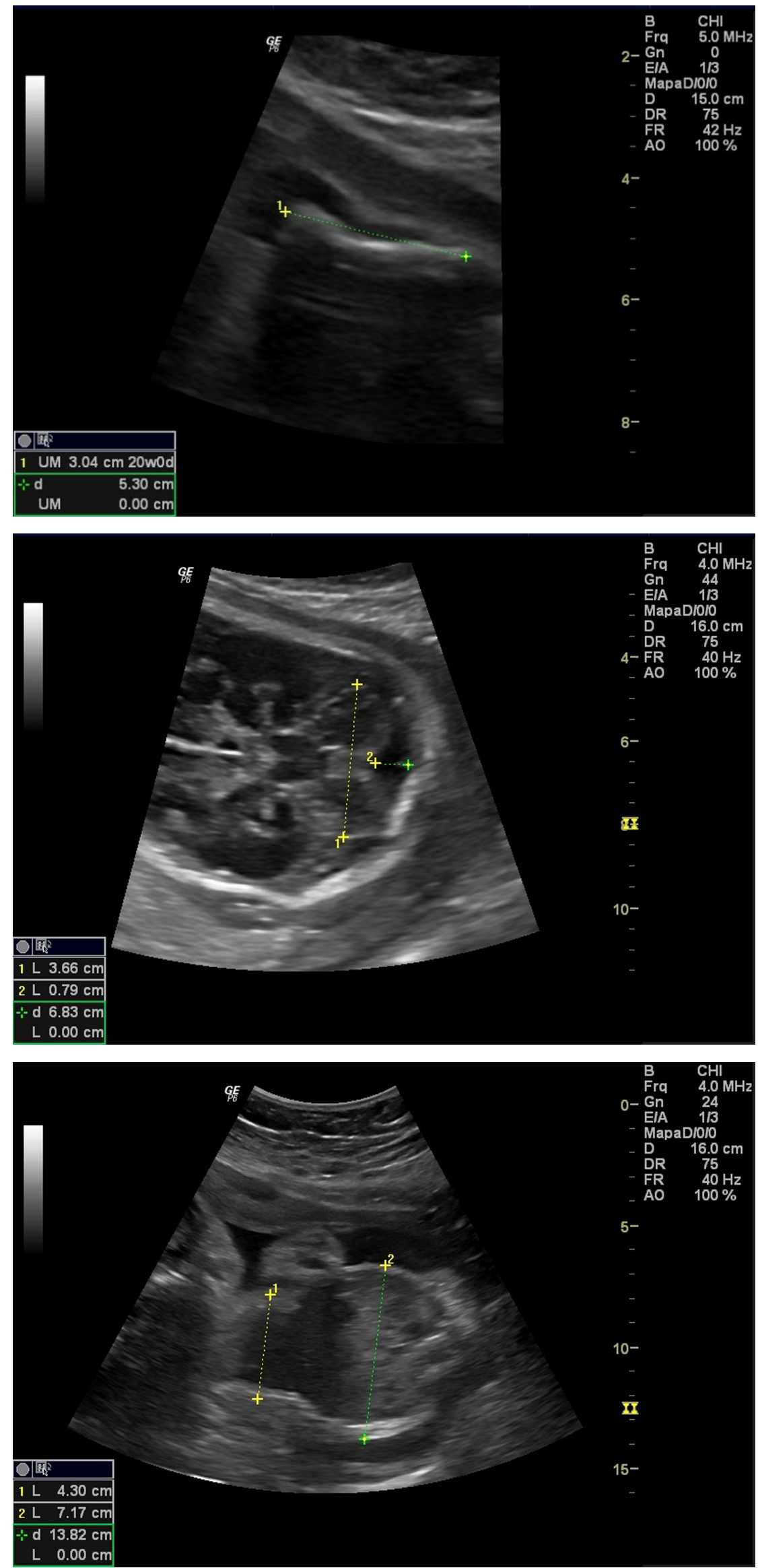

Figura 1. Identificado o úmero curto e arqueado na ultrassonografia obstétrica.
Figura 2. Corte trans-cerebelar ultrassonográfico, evidenciando a deformidade da calota craniana à mínima pressão do transdutor no abdome materno.
Figura 3. A ultrassonografia identifica tórax estreito contrastando com a circunferência abdominal normal para a idade gestacional. 

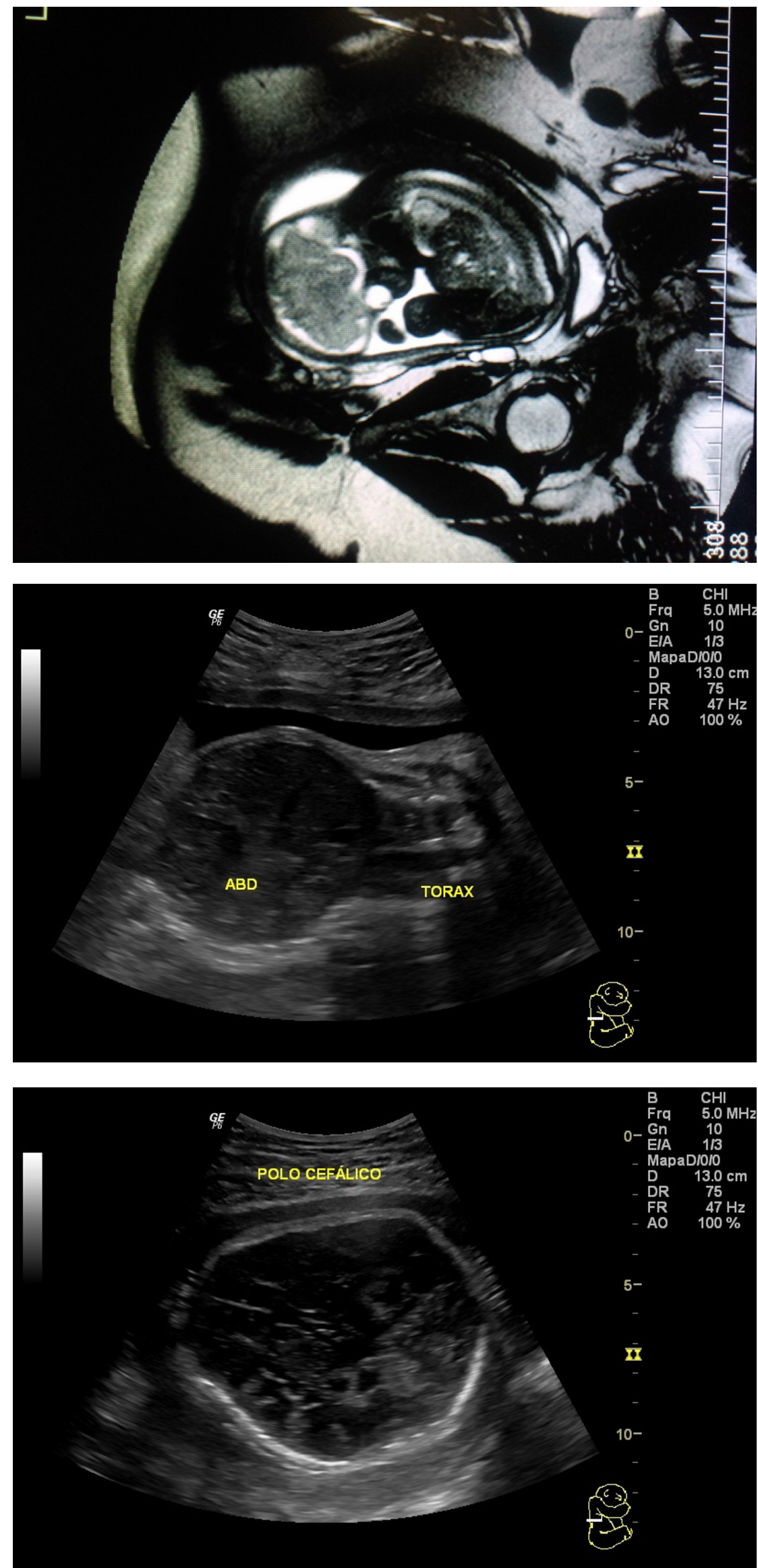

Figura 4. Imagem obtida através da ressonância magnética fetal, evidenciando membros curtos e falta de mineralização óssea, mais pronunciada no crânio.

Figura 5. Relação tórax/abdome com 33 semanas e quatro dias à ultrassonografia,

mantendo diminuição torácica em relação à abdominal.

Figura 6. A ultrassonografia no terceiro trimestre da gestação identifica o polo cefálico fetal com aspecto de desmineralização 


\section{DISCUSSÃO}

A OI corresponde a um grupo de distúrbios do tecido conjuntivo que apresenta formas letais e não letais [1]. Assim como em todas as malformações congênitas, que representam atualmente a segunda causa de morte infantil no Brasil, é importante o seu diagnóstico precoce e um acompanhamento pré-natal adequado [3].

O seguimento de um feto com OI requer uma equipe multidisciplinar, que tem como objetivo melhorar a expectativa e a qualidade de vida (mobilidade, independência e integração social) nas formas mais brandas da doença, embora não se disponha de medicação específica para o tratamento $[1,3]$. Tanto nas formas brandas quanto nas formas mais graves, é importante o apoio à gestante e à família, pois frente ao diagnóstico, são comuns a surpresa, o desapontamento, a ansiedade e a negação [8]. Esse atendimento foi ofertado à gestante no presente caso, o que garantiu a sua calma durante a transferência de hospital para o parto.

A ultrassonografia obstétrica possibilita o diagnóstico de OI mesmo antes da viabilidade fetal, a partir das 17 semanas [7] e, independente da variável clínica, o encurtamento de ossos longos é o mais frequente e mais precoce achado dessa doença $[3,4,6]$. Isto corrobora com a afirmação de que a ultrassonografia torna-se imperativa no pré-natal, permitindo o acompanhamento da gestação em serviço terciário como neste relato [5].

Um estudo de revisão sobre o diagnóstico intrauterino de OI identificou como achados ultrassonográficos exclusivos no tipo 2 da doença: tórax em sino ou hipoplásico, redução da calcificação craniana, osteopenia, platispondilia, bossa frontal e aumento dos ventrículos cerebrais, enfatizando a sua expressiva gravidade clínica [3], com formato wormiano (irregular) dos ossos do crânio [8]. Sendo que o primeiro e segundo achados, identificáveis neste caso, nortearam a hipótese diagnóstica antenatal.

Outras displasias esqueléticas letais, como acondrogênese ou hipofosfatasia, foram descartadas durante a análise do caso. A primeira cursa com outros achados ultrassonográficos, sendo característicos a cabeça grande, hipomineralização dos corpos vertebrais e ossos encurtados, porém de formato habitual; e a segunda apresenta um encurtamento leve a moderado dos ossos longos e ausência da calcificação do crânio - achados não presentes no caso descrito [9].

Para auxílio, complementação ou diagnóstico diferencial pós-nascimento da OI, a equipe médica pode fazer uso de método simples, barato e disponível na maioria dos hospitais: a radiografia. Nesse exame nota-se principalmente a falta de ossificação do crânio, a deformidade dos ossos longos e costelas em rosário com inúmeras fraturas [4]. No caso relatado, esse exame não foi julgado necessário pela equipe responsável pelo atendimento ao recém-nascido.

$\mathrm{Na}$ OI tipo 2 o deve ser ofertado ao casal o aconselhamento genético, pelo risco de recorrência de 6 a $8 \%$, devido à possibilidade de mosaicismo gonadal [3]. O aconselhamento pode ser feito pela análise de células do líquido amniótico envolvidas na síntese do pró-colágeno, obtidas por amniocentese [7]. Contudo, estudos reforçam que o cariótipo não deve ser visto como um meio de diagnóstico deste tipo de patologia, mas sim como um exame para excluir alterações cromossômicas [6]. A possibilidade desse exame foi discutida e explicada para a gestante e familiares, que não consentiram no procedimento.

Quando o diagnóstico de uma malformação congênita letal é feito durante o pré-natal, tornase importante, além do aconselhamento genético, informar os pais sobre a possibilidade de interrupção da gestação [10]. Em países como Dinamarca, Grécia e Portugal, o aborto é assegurado por lei, mas no Brasil a legislação permite a interrupção apenas nos casos de anencefalia, de gestação proveniente de estupro e quando existe risco para a vida da gestante; outros casos são avaliados por demanda judicial [10].

A via de parto para fetos com diagnóstico de OI ainda é controversa, com tendência à cesariana, como foi a opção da equipe responsável pelo parto neste caso [4], porém sem estudos que suportem essa decisão [1]. Assim, nos casos de OI tipo 2, o riscobenefício de uma cesariana deve ser abordado nas consultas de pré-natal, explicitando-se que a via de parto parece não alterar o prognóstico do recémnascido [2]. Da mesma forma, nos tipos não letais de OI, o parto vaginal pode ser uma opção, sem aumento do número de fraturas no feto durante o trabalho de parto e no momento do parto [1].

Ressaltamos que alguns fetos com diagnóstico de OI tipo 2 podem sobreviver alguns minutos e mesmo horas, devendo-se garantir um atendimento que não leve à distanásia e prime pelo conforto do paciente, com mínimo manuseio devido ao risco de fraturas adicionais. Manter em unidades de calor radiante, garantir a monitorização dos sinais vitais e assistência ventilatória mínima, não estando indicadas a ressuscitação ou medidas heroicas [11].

Assim, nossa intenção foi a de relatar um caso letal de OI e ressaltar a importância do diagnóstico prénatal através da ultrassonografia, para o seu manejo adequado. Isto para garantir o acolhimento familiar antes, durante e após o parto, em uma gestação considerada, inicialmente, de baixo risco. 


\section{REFERÊNCIAS}

1. Souza ASR, Cardoso AS, Lima MMS, Guerra GVQL. Diagnóstico pré-natal e parto transpelviano na osteogênese imperfeita: relato de caso. Rev Bras Ginecol Obstet. 2006;28(4):244-50. http://dx.doi.org/10.1590/S0100-72032006000400007

2. Lyra TG, Pinto VAF, Ivo FAB, Nascimento JS. Osteogenesis Imperfecta em obstetrícia: Relato de caso. Rev Bras Anestesiol. 2010;60(3): 321-4. http://dx.doi.org/10.1590/s0034-70942010000300011

3. Sillence DO, Senn A, Danks DM. Genetic heterogeneity in osteogenesis imperfecta. J Med Genet. 1979;16:101-16. http://dx.doi org/10.1136/jmg.16.2.101

4. Lima JS, Nunes VRT, Souza RFF, Campos AS, Aguiar RALP, Aguiar MJB. Osteogênese imperfeita perinatal na Maternidade do Hospital das Clínicas da UFMG. Rev Med Minas Gerais. 2010;20(4):483-9.

5. Betat RS, Telles JAB, Sanfelice FS, Fell PRK, da Cunha AC, Picetti J, Bedin C, Rosa RFM. Achados pré e pós-natais de um caso de osteogênese imperfeita do tipo II (forma letal). Revista HCPA. 2012;32(4):512-4.

6. Araújo Junior E, Zanforlin Filho SM, Guimarães Filho HA, Pires CR, Santana RM, Nardozza LMM, Moron AF. Diagnósticos das malformações e tumores fetais: aspectos iconográficos à ultra-sonografia bidimensional e tridimensional. Rev imagem. 2006;28(1):25-32.

7. Martins MM, Macedo CV, Carvalho RM, Pinto A, Alves MAM, Graça LM. Prenatal diagnosis of skeletal dysplasias - a ten-year case review. Acta Obstet Ginecol Port. 2014;8(3):232-9.

8. Lima Rodríguez UD, Hernández Rodríguez AR, Pérez Espinosa LM, Alberro Fernández M. Osteogénesis imperfecta tipo II. Reporte de 1 caso. Rev Cubana Ortop Traumatol. 1999;13(1-2):115-8.

9. Bomfim OL, Coser O, Moreira MEL. Unexpected diagnosis of fetal malformations: therapeutic itineraries. Rev de Saúde Coletiva, Rio de Janeiro. 2014;24(2):607-22. http://dx.doi.org/10.1590/s0103-73312014000200015

10. Zen PRG, Silva AP, O. Filho RL, Rosa RFM, Maia CR, Graziadio C, Paskulin GA. Diagnóstico pré-natal de displasia tanatofórica: papel do ultrassom fetal. Rev Paul Pediatr. 2011;29(3):461-6. http://dx.doi.org/10.1590/S0103-05822011000300024

11. Oliveira FR, Camargos AF. Descriminalização do aborto de anencéfalos: a conquista de um direito e o início de vários dilemas éticos Femina. 2011;39(6):123-4.

12. Moreira M, Lopes JMA e Carvalho M. O recém-nascido de alto risco: teoria e prática do cuidar [online]. Rio de Janeiro: Editora FIOCRUZ; 2004. 564 p. 